\title{
Federica Matta, Le Voyage des imaginaires
}

\section{Elena Pessini}

\section{(2) OpenEdition}

\section{Journals}

\section{Édition électronique}

URL : https://journals.openedition.org/studifrancesi/21799

DOI : 10.4000/studifrancesi.21799

ISSN : 2427-5856

\section{Éditeur}

Rosenberg \& Sellier

\section{Édition imprimée}

Date de publication : 1 décembre 2019

Pagination : 617-618

ISSN : 0039-2944

\section{Référence électronique}

Elena Pessini, « Federica Matta, Le Voyage des imaginaires », Studi Francesi [En ligne], 189 (LXIII | III) | 2019, mis en ligne le 01 mars 2020, consulté le 11 novembre 2021. URL : http://

journals.openedition.org/studifrancesi/21799; DOI : https://doi.org/10.4000/studifrancesi.21799

Ce document a été généré automatiquement le 11 novembre 2021.

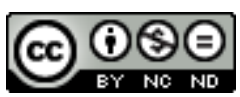

Studi Francesi è distribuita con Licenza Creative Commons Attribuzione - Non commerciale - Non opere derivate 4.0 Internazionale. 


\title{
Federica Matta, Le Voyage des imaginaires
}

\author{
Elena Pessini
}

\section{RÉFÉRENCE}

Federica Matta, Le Voyage des imaginaires, Les foudres Édouard Glissant, Habitation Saint-Étienne, Martinique, 2018, 24 pp.

Il serait par trop réducteur d'écrire que ce bel ouvrage est le catalogue de l'exposition homonyme, réalisée par Federica Matta en Martinique de décembre 2016 à avril 2018, qui présentait une cinquantaine d'œuvres sur toile et sur papier. Ce grand livre, qui est double puisqu'il en abrite un autre intitulé Mon cahier de la Martinique, raconte, tout comme l'a fait l'exposition qui l'a précédé, la rencontre entre l'écrivain Édouard Glissant et l'artiste qui fut autrefois son élève à l'Institut Martiniquais d'Études (IME); une rencontre parfaitement définie dans la préface écrite par Patrick Chamoiseau («Federica de toutes les grâces»): «Federica Matta a connu cette conjonction inouïe qui accorde des pluriels. Une rencontre. La rencontre. Tout à la fois celle d'un homme, d'un pays et d'une œuvre» (p. 1). Les aphorismes maintenant devenus célèbres d'Édouard Glissant se mêlent aux couleurs, aux lignes, aux formes de Federica Matta qu'ils inspirent. Un véritable dialogue s'instaure entre le monde imaginé par l'écrivain et penseur martiniquais où «Rien n'est vrai, tout est vivant», où «Je peux échanger avec l'Autre sans me perdre ni me dénaturer», et l'univers à la fois magique et réel créé par le peintre. Les mots d'Édouard Glissant se glissent dans les dessins, les illuminent, les complètent, les nuancent, au sein d'une harmonie surprenante, les mots des phrases ciselées comme des pierres, polies au fil des années et de l'évolution de la pensée glissantienne, les mots des formules lapidaires mais aussi les vers des Indes, le long poème épique publié par Édouard Glissant en 1956, qui a la part belle, choisi entre toutes les œuvres de l'écrivain martiniquais. Les six Livres des Indes (L'Appel, Le Voyage, La Conquête, La Traite, Les Héros, La Relation) défilent sous les yeux du lecteur. Federica Matta relit le texte en même temps qu'elle lui offre une visibilité graphique, une 
plasticité et souligne ainsi le caractère central de cette œuvre dont la date de publication pourrait laisser croire qu'il s'agit d'une œuvre de jeunesse mais dont la lecture attentive confirme qu'elle se situe au cœur de la production glissantienne, qu'elle en trace le développement et les grands axes. Matta dessine le rêve des découvreurs, les affres des voyages de la Traite et de la conquête, le sang qui a été versé dans une ronde de couleurs qui fascine et invite à la réflexion.

Protégé comme dans un écrin, sous la forme d'un livret en noir et blanc où Federica Matta utilise ses propres mots et ses dessins, Mon cahier de la Martinique raconte la belle histoire personnelle de la jeune fille qui débarque en 1970, alors qu'elle est âgée de 15 ans, dans l'île des Caraïbes pour suivre les cours de l'Institut Martiniquais d'Études, école fondée par Édouard Glissant et pour vivre ce qui restera pour elle une expérience unique et inoubliable. Ce témoignage, composé de 11 textes numérotés, est passionnant sous bien des aspects. Il raconte une époque pétrie des rêves de l'élan social et culturel de 1968; les parents de Federica - son père est le célèbre artiste chilien Roberto Matta envoient leur fille pour un séjour en Martinique afin qu'elle se forme au sein de cette école expérimentale qui propose des programmes innovateurs, des maîtres d'exception, une école voulue par Glissant pour offrir une formation différente par rapport au cursus traditionnel du parcours imposé par le système scolaire français en Martinique: «Je me souviens de la liste de lecture qui nous était donnée le premier jour de classe. Je me souviens de la petite feuille qui disait: Édouard Glissant, La Lézarde, Franz Fanon, Peau noire, masques blancs, Aimé Césaire, Cahier d'un retour au pays natal, Karl Marx, Le Manifeste du parti communiste, André Breton, Le Manifeste du Surréalisme, Pablo Neruda, Le Chant général, Henri Michaux, La Ralentie» (p. 11). Federica Matta fournit également une mine d'informations précieuses sur le fonctionnement de l'Institut, sur la passion qui anime tous ceux qui y travaillent et sur une méthode d'enseignement véritablement révolutionnaire où la poésie, le théâtre, l'initiative et la réflexion personnelle des étudiants sont tenus en très haute considération: «Dans nos classes, l'histoire était lue par la géographie, elle-même chantée par la philosophie, méli-mélos mêlés aux vents et aux pluies qui entraient par les fenêtres. Notre école nous démontrait à travers nos échanges avec nos professeurs qu'il était possible de participer à la vie du monde par une Poétique de la Politique» (p. 22).

L'ouvrage est aussi le récit de l'expérience personnelle d'une artiste qui est à l'écoute de ce qui a fait naître son inspiration, qui effectue une plongée dans son passé en ayant aujourd'hui pleinement conscience de l'importance de son aventure martiniquaise. Il s'agit bien d'un hommage vibrant à Édouard Glissant et un parfait exemple de la richesse des dialogues entre les artistes et les créateurs. Si Federica Matta exprime sa dette envers celui qui fut autrefois son professeur, Glissant prend la parole en conclusion de l'ouvrage avec ces mots qui racontent si bien l'œuvre de celle qui fut autrefois son élève: «Elle dessine et elle peint dans toutes les langues du monde: c'est par là que Federica Matta fréquente une innocence sacrée, celle des débuts de tout langage et des premiers mots du poème, celle des légendes d'étoiles et des souffrances et des ignorances, qui font encore les histoires des peuples» (p. 24). 